Discussion Paper No. 14-091

\title{
Staging Innovation Projects: (When) Does it Pay Off?
}

Petra Andries and Paul Hünermund

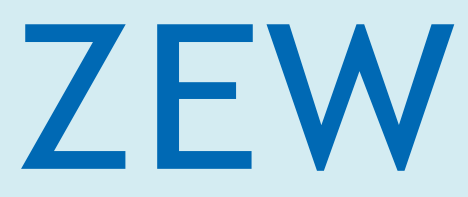

Zentrum für Europäische Wirtschaftsforschung $\mathrm{GmbH}$ Centre for European Economic Research 
Discussion Paper No. 14-091

\title{
Staging Innovation Projects: (When) Does it Pay Off?
}

\author{
Petra Andries and Paul Hünermund
}

Download this ZEW Discussion Paper from our ftp server:

http://ftp.zew.de/pub/zew-docs/dp/dp14091.pdf

Die Discussion Papers dienen einer möglichst schnellen Verbreitung von neueren Forschungsarbeiten des ZEW. Die Beiträge liegen in alleiniger Verantwortung der Autoren und stellen nicht notwendigerweise die Meinung des ZEW dar.

Discussion Papers are intended to make results of ZEW research promptly available to other economists in order to encourage discussion and suggestions for revisions. The authors are solely responsible for the contents which do not necessarily represent the opinion of the ZEW. 


\title{
Staging innovation projects: (When) does it pay off?
}

\author{
Petra Andries* $\quad$ Paul Hünermund ${ }^{\dagger \dagger}$
}

November 2014

\begin{abstract}
Building on real options literature, this study shows that the use of a staged approach for the management of innovation projects affects the innovation output of firms differently depending on firm characteristics and ambitions. In particular, while staged project management increases the effect of innovation expenditures on new product sales for firms envisaging incremental or continuous innovations, this moderating effect is absent for firms aspiring radical innovations. In addition, while staged project management has a positive moderating effect in firms with resource slack, this is not the case when firms are resource-constrained. We further investigate the underlying mechanisms to this latter finding by demonstrating that in resource-abundant firms staged project organization is associated with delaying projects until more information becomes available. Thereby these firms reap the waiting value inherent to real options reasoning. By contrast, resource-constrained firms using staged project management are shown to abandon a larger share of their innovation projects and to concentrate resources on fewer projects. It appears, however, that, due to budgetary pressure, they make the decision to abandon at a too early stage where uncertainty is insufficiently resolved. This can explain why there is no effect of staged project management on the sales of resource-constrained firms from new products. The paper contributes to theory development on when and why the staging of innovation projects affects the innovation output of firms and to the literature on real options reasoning in general.
\end{abstract}

Key words: staging of innovation projects, real options theory, new product development process, ressource allocation, innovation portfolios

JEL classification: $\mathrm{O} 32, \mathrm{M}$

${ }^{*}$ Ghent University, Faculty of Economics and Business Administration. e-mail: petra.andries@ugent.be

${ }^{\dagger} \mathrm{KU}$ Leuven, Department of Managerial Economics, Strategy and Innovation

${ }^{\ddagger}$ Centre for European Economic Research, Department of Industrial Economics and International Management 


\section{INTRODUCTION}

For firms to survive in the long run, the development and commercialization of new products and services are essential. Even in tough economic and budgetary times, firms have to keep investing in innovation projects of which the outcome is often highly uncertain (Hauser et al., 2006; Brown and Eisenhardt, 1997). The organization and financing of innovation projects in different stages is widely accepted - both in academic literature and in practice - as the preeminent way of managing and even benefiting from uncertain opportunities while keeping costs under control (Cooper, 2008).

Surprisingly however, empirical evidence on the performance effect of staging innovation projects is scarce. On the one hand, the innovation economics literature investigates the relationship between innovation expenditures and innovation output without taking project organization and project financing into account (see also Klingebiel and Rammer, 2014). On the other hand, the innovation management literature elaborates on the potential advantages and limitations of staging innovation projects (Ettlie and Elsenbach, 2007; Oorschot et al., 2010; Biazzo, 2009) and shows that an increasing number of firms have formalized their project management processes as a staged process (Griffin, 1997; Barczak et al., 2009). However, quantitative evidence on the impact of staged project management on firms' innovation output is largely absent. As a result, it is still unclear whether and, perhaps even more importantly, under which conditions the staging of innovation projects makes sense.

The goal of this paper is therefore to empirically examine whether and under which conditions the staging of innovation projects moderates the relationship between firms' investments in innovation and their innovation output, and in particular on sales from new products. It thereby contributes to a growing stream of literature aiming to uncover how differences in innovation management and strategy contribute to the innovation output of firms (Laursen and Salter, 2006; Klingebiel and Rammer, 2014).

The basic principle of staged project management is that projects only proceed to subsequent stages if certain predefined criteria, mostly related to technological feasibility, costs, and market response are met. Only projects that pass these gates receive followup financing. Staged project management hence allows firms to postpone commitment until a potentially substantial portion of the uncertainty about the opportunity has been resolved (Adner and Levinthal, 2004). In that respect, staging innovation projects is very similar to buying a series of options on an investment (Cooper, 2008). It offers the firm the value of waiting for additional information before investing more, and the value of abandoning projects that turn out to be insufficiently promising.

However, the literature suggests that the organization of innovation projects in stages also has several limitations. First, the approach entails a significant risk of killing potentially "right" projects at the early gates (Oorschot et al., 2010), whereas with slightly more time and resources, these may have been met and the project may have turned to become very successful (Adner and Levinthal, 2004). Secondly, abandoning innovation projects at an early stage reduces the odds of discovering a wide variety of related opportunities. Unsuccessful experiments do not only provide information on their viability, but may also lead to the discovery of unforeseen opportunities (Adner and Levinthal, 2004). 
In line with a large body of research pointing to the need for a contingent approach in the design of new product development processes (Benner and Tushman, 2003; Shenhar and Dvir, 1996; for an overview see Biazzo, 2009), it makes sense to investigate not only whether the staging of innovation processes positively moderates the relationship between firms' investments in innovation and their innovation output, but also under which circumstances this is the case.

In particular, we hypothesize that the positive moderating effect of staging innovation projects is smaller for resource-constrained firms and for firms envisaging more radical innovations. We test these hypotheses by combining credit rating information with data from two waves of the German section of the Community Innovation Survey (CIS), which is an official survey by the European Commission launched across Europe. These data are suitable since they include the sales from new products as a measure of innovation output. In addition to the standard catalog of CIS questions, these two editions also include questions on the management of innovation projects, and in particular on whether these projects are organized and financed in stages.

Our analyses demonstrate that the staging of innovation projects strengthens the effect of innovation expenditures on new product sales in firms with resource slack, but not in resource-constrained firms. A further investigation shows that in resource-abundant firms the staging of innovation project is associated with delaying projects. This indicates that they postpone decisions until more information becomes available, thereby reaping the option value inherent in waiting. By contrast, resource-constrained firms that use staged project management abandon individual projects more frequently and thereby focus resources on a lower number of projects. This selection of projects is, however, ineffective in stimulating innovation output, which suggests that, because of budgetary pressure, resource-constrained firms need to decide on abandonment at points in time when uncertainty is insufficiently resolved. Resource-constrained firms are thereby not able to capture the option value of abandonment. In addition, while the moderating effect of staging innovation projects is significantly positive for firms envisaging incremental or continuous innovations, the predetermined milestones and criteria inherent to staged project management are apparently less appropriate for developing more radical innovations. Firms envisaging radical innovations do not benefit from staging their innovation projects. Overall, staged project management only works for resource-abundant firms that aspire incremental innovations.

This study contributes to theory development in the area of innovation management and real options reasoning by delineating how differences in the management of innovation projects explain variances in the innovation output of firms. In particular, we theorize how the staging of innovation projects moderates the translation of innovation expenditures into innovation output, and how this moderating effect depends on resource availability and on the radicalness of the envisaged innovations. Our findings have important implications for resource-constrained as well as resource-abundant firms aiming to optimize their innovation processes.

In the remainder of the paper we review the literature to develop our hypotheses. We then explain the empirical approach and results and conclude with a discussion of the implications of our study for theory and practice. 


\section{LITERATURE AND BACKGROUND}

As an essential determinant of long-run survival, the development and commercialization of new products and services will constitute a substantial share of firms' investments. According to Klingebiel and Rammer (2014, pp. 248), "the success of a firm's suite of innovative activities is a function of the amount and quality of resources dedicated to the task". However, even more than the injection of resources into innovation activities, the way these innovation expenditures are employed will determine to which extent a firm succeeds in the commercialization of innovation activities. This study adds to a growing stream of literature aiming to uncover how differences in innovation management and strategy contribute to the innovation output of firms (Laursen and Salter, 2006; Klingebiel and Rammer, 2014). In particular, it investigates whether the staging of innovation projects allows a firm to reap better results from investments in innovation.

However, assuming that the staging of innovation projects has the same effect in all firms and for all types of innovations would be a rash conclusion. As summarized by Biazzo (2009), a large body of research has pointed to the need for a contingent approach in the design of new product development processes, highlighting the risk of a one-sizefits-all approach (Loch, 2000; Phillips et al., 2006; Benner and Tushman, 2003; Shenhar and Dvir, 1996). The literature on real options reasoning, which can be regarded as the theoretical framework underlying the staging of innovation projects, has only recently identified firm-specific factors as possible determinants of performance heterogeneity across firms (Driouchi and Bennett, 2012; Tong and Reuer, 2006, 2007). Neglecting these firm-specific factors might explain why existing studies often lead to incomplete or conflicting conclusions (Driouchi and Bennett, 2012). The current study intends to fill this gap by explicitly taking into account resource availability and the radicalness of envisaged innovations when examining the impact of staged project management.

\subsection{Staging innovation projects}

As the outcome of innovation projects is often highly uncertain, academics and practitioners have been searching for ways to tackle this uncertainty. The organization and financing of innovation projects in different stages has been widely proposed as the preeminent way of managing and even benefiting from uncertain opportunities while keeping costs under control. The staging of innovation projects involves "a conceptual and operational map for moving new product projects from idea to launch and beyond" (Cooper, 2008, pp. 214). It comprises a series of stages where at the end of each stage a decision is made to either abandon or continue with the project. Organizing the innovation process in stages makes the size of an investment inversely proportional to the investment's uncertainty. At early stages, when uncertainty regarding the technical and commercial viability of the innovation project is typically high, investments are relatively limited. As uncertainty is reduced, the projects that have not been killed advance to subsequent stages where funding increases (Summers and Scherpereel, 2008).

The theoretical underpinning for the staging of innovation projects can be found in real options theory. This theory is concerned with investments in real assets with a structure 
similar to that of financial options (Bowman and Hurry, 1993; Dixit and Pindyck, 1994). As Cooper (2008, pp. 214) points out, organizing innovation projects in stages "is very similar to [...] buying a series of options on an investment. Initially, one purchases an option for a small amount of money, then does some due diligence, and finally decides whether or not to continue to invest". This results in a sequence of smaller irreversible investments (Dixit and Pindyck, 1994), which offers an alternative to traditional upfront investment. As pointed out by McGrath (1999), staging investments can lower the cost of mistakes. "If investments are staged so that expenditures end under poor conditions, losses can be contained. The cost of failure, in other words, is limited to the cost of creating the real option, less any remaining option value" (McGrath, 1999, pp. 14). This freedom to abandon an unsuccessful innovation project at low cost frees up financial resources which would otherwise be spent on the continuation of the project. These additional resources can be invested in other more promising innovation projects, thereby contributing to the innovation output of the firm. In addition, there is also value in waiting to invest (McDonald and Siegel, 1986). Even if the technical development of a product is successful, the market may not be ready yet. The option to wait longer before commercializing the product can create higher sales in the longer turn. In general, a staged approach allows firms to postpone commitment until a substantial portion of the uncertainty about the opportunity has been resolved (Adner and Levinthal, 2004). Given the value of abandonment and the value of waiting inherent to staging of innovation projects, we posit that an additional investment in innovation projects contributes to innovation output more if these projects are organized in stages. In other words:

H1: Staged project management has a positive moderating effect on the relationship between innovation inputs (i.e., innovation expenditures) and innovation outputs (i.e., sales from new products).

\subsection{Resource availability}

A first possible contingency factor identified in the literature is resource availability. In staged innovation projects, the project team has a stipulated budget at its disposal to make it to the first milestone. If this milestone is not met with the given budget, the project is killed. A study by Oorschot et al. (2010) indicates that a small increase in early project stage investment can have a substantial impact on overall innovation success. Under tight budget constraints, projects that could eventually become successful are not seldom cut at a too early stage. Lower budgets cause delays in assembling the project team and hence lead to temporary understaffing, which in turn results in a higher number of undetected errors and an increased need for rework. Consequently, projects do not reach their initial milestones and are abandoned. Slightly relaxing budget constraints avoids these problems and leads to an increased accomplishment of initial milestones as well as a reduction in overall project costs.

In addition, the literature suggests that firms must be equipped with resource-costly systems and capabilities to detect and develop real options before actually being able to benefit from a real options approach. First, identifying and developing different 
options requires sufficient financial and human resources. If a project is abandoned, the company needs to search its reserve of alternative option prospects (Kogut, 1989; Kogut and Kulatilaka, 1994; Rangan, 1998). Furthermore, firms need to appropriate operational routines to avoid being caught in the pitfalls of real options reasoning, such as suboptimal decision-making due to social ties and cognitive biases (Coff and Laverty, 2001) and the tendency to escalate commitment in the face of abandonment (Carr, 2002; Adner, 2007; Adner and Levinthal, 2004). Finally, resource availability and learning capabilities are crucial for absorbing the full potential of firms' option reserves (Barnett, 2008; Miller, 2002; Miller and Arikan, 2004). As Tong and Reuer (2007) point out, real options reasoning generally leads to increased marginal costs from both greater coordination complexity and greater information load born by managers. For example, the new product development literature posits that staging the innovation process may distance the final product from the original idea if information dependencies are not managed well (Crawford and Di Benedetto, 2008). Project managers are assumed to accumulate competently all relevant information as a new product progresses through the stages (Hart et al., 2003; Huber, 1991; Song et al., 2007). Resource-constrained firms may not have the financial and human capabilities to manage these complex processes.

As the literature suggests that companies with fewer financial resources are more likely to exit potentially projects, and are insufficiently staffed to deal with the greater complexity inherent to staging innovation projects, we hypothesize they generally benefit less from staging their innovation projects. In other words:

H2: The moderating effect of staging innovation projects is lower for resourceconstrained firms than for resource-abundant firms.

\subsection{Radicalness of envisaged innovations}

As pointed out by Klingebiel and Rammer (2014), firms differ with respect to the radicalness of the new products they intend to develop. In particular, a distinction can be made between continuous or incremental innovations on the one hand, and radical innovations on the other hand. Incremental innovations include the improvement of existing technologies and products, whereas radical innovations encompass the creation of completely new products and competencies (Zaltman et al., 1973; Abernathy and Utterback, 1987; Dewar and Dutton, 1986). While some companies focus on projects that are closely related to their existing products and capabilities, others put more effort into the development of radical innovations that are further apart from their existing knowledge base (Hauser et al., 2006; Shane and Ulrich, 2004). We posit that a firm's focus on incremental versus radical innovations is an important contingency factor for the staging of innovation projects.

Staged project management requires the upfront identification of milestones and criteria for continuation or abandonment. This works well when projects have a fixed technical agenda and fixed target market (Adner and Levinthal, 2004), and when commercialization issues and the development of institutional structures can be considered sequential to technological issues, as is the case for continuous or incremental innovations 
(Garud et al., 1998). When more radical product innovations are envisaged, discovering a wide variety of alternatives even in the face of initial negative results becomes crucial. Although a project may not meet its initial expectations, it can lead to the discovery of unanticipated possibilities and thereby enable the development of radical innovations. Staged project management with predetermined milestones and criteria does not seem appropriate for the development of this type of radical innovations, where goals are often unclear. Under such circumstances, a more experimental approach may be preferable, where deliverables are flexible and detours are possible (Eisendardt and Tabrizi, 1995). As Adner and Levinthal (2004, pp. 77) put it, "imposing rigid criteria for abandonment may result in the underutilization of discoveries made in the context of initiatives that are failures with respect to their initial agenda but that introduce promising possibilities not previously imagined". We therefore argue that the moderating effect of staging innovation projects depends on whether a firms intends to develop incremental or radical innovations. In other words:

H3: The moderating effect of staged project management is lower for firms envisaging radical innovations than for firms envisaging incremental innovations.

\section{DATA AND ESTIMATION}

\subsection{Sample}

The Mannheim Innovation Panel (MIP) is an annually conducted innovation survey of German firms and part of the pan-European Community Innovation Survey (CIS). Each year, a number of questions not included in the standard CIS instrument is added for purposes of academic research, such as the items used in this article. The MIP is a stratified (according to sector, size class and region) random sample that complies to the guidelines and definitions of the Oslo Manual (OECD, 2005) for surveys on innovation activities. The MIP covers all production sectors (sections B, C, D, E according to the NACE Rev. 2.0 classification) and a large number of service sector $(\mathrm{H}, \mathrm{J}, \mathrm{K}, \mathrm{N}$, division 46) including business-related services (divisions 69, 70.2, 73, 74), architecture and engineering (71), and research and development (72). The use of CIS data has a long-standing tradition in economics of innovation (Crépon et al., 1998; Cassiman and Veugelers, 2002; Belderbos et al., 2004; Czarnitzki and Toole, 2011; Czarnitzki and Hottenrott, 2011b; Peters et al., 2013). Recent contributions show an increased attention also by management scholars (Laursen and Salter, 2006; Leiponen and Helfat, 2010, 2011; Klingebiel and Rammer, 2014).

Items relevant to our research hypotheses are contained in the 2009 (covering the years 2006 until 2008) and 2011 (2008 until 2010) waves of the MIP. The gross samples include 35, 195 (2009) and 35,531 (2011) firms; net response rates (adjusted for neutral losses) amount to $22.3 \%$ (2009) and $23.6 \%$ (2011), leading to 7,061 (2009) and 6,851 (2011) responses, respectively. Compared to other national contributions to the CIS, participation in Germany is rather low, which can mainly be explained by the fact that survey 
Table 1: Summary Statistics

\begin{tabular}{lcccc}
\hline \hline \multicolumn{1}{c}{ Variable } & Mean & Std. Dev. & Min. & Max. \\
\hline New Product Sales (MM $€$ ) & 23.42 & 407.45 & 0 & 24191 \\
Innovation Intensity (MM € per empl.) & 0.0102 & 0.0171 & 0 & 0.1025 \\
Firm Size (number of employees) & 393.7 & 3694.08 & 1 & 186000 \\
Firm Age & 31.56 & 36.9 & 1 & 509 \\
Projects $^{\dagger}$ & 15.41 & 89.49 & 1 & 4598 \\
Credit Rating $^{\ddagger}$ & 223.4 & 44.22 & 100 & 500 \\
Share of Graduates $_{\text {Staged }^{\dagger}}$ & 0.26 & 0.27 & 0 & 1 \\
Radicalness $^{\dagger}$ & 0.62 & & 0 & 1 \\
Process Innovation $^{\dagger}$ & 0.34 & & 0 & 1 \\
Group $^{\dagger}$ & 0.61 & & 0 & 1 \\
\hline
\end{tabular}

Sample size: $N=3853$

$\dagger$ Variables that cover a period of $t$ until $t-2, \ddagger$ credit rating in period $t-1$

participation is not mandatory unlike in other European countries, while the questionnaire is significantly longer and more complex. To this end, the survey is accompanied by an extensive non-response analysis through individual telephone interviews compared to the main survey instrument, which allows the respondents to choose between a mail or online questionnaire. Due to its extensive scope, with items that go beyond the standard catalog of CIS questions, annual surveys, and a careful quality control, the MIP data is generally considered to be of high quality (Klingebiel and Rammer, 2014). We drop firms that do not report any kinds of innovation activities (including the attempt to innovate) from the full sample since our analysis is concerned with the question of how firms that have already decided to engage in innovation activities organize this process. The estimation sample that has been corrected for missing values contains 3,853 observations, i.e., 2, 122 observations from the 2009 wave and 1,731 observations from the 2011 wave.

\subsection{Main variables}

We measure firms' innovation performance as the absolute number of sales that are achieved with new products (New Product Sales) in a given year. To classify a product as "new", it must be a product or service that is newly introduced, or its components or basic characteristics need to be significantly improved. Firms in our sample report average sales of 23.4 million euros stemming from new products (see Table 1). The distribution is substantially right-skewed and ranges from zero up to more than 24 billion euros. The concept of New Product Sales as an outcome measure is well-established in the literature (Laursen and Salter, 2006; Klingebiel and Rammer, 2014; Cappelli et al., 2014). 
The total amount of expenditures for innovation activities by a firm is our main measure of input to the innovation process. It covers all types of $\mathrm{R} \& \mathrm{D}$ and basic research (including expenditures for personnel, capital and contract R\&D) as well as expenditures in later stages of the innovation process, such as for training and market preparation (OECD, 2005, Section 4.1). We scale expenditures by the number of employees to arrive at a measure (Innovation Intensity) that adjusts for mere size effects. To reduce noise due to outliers and reporting mistakes, we winsorize observations above the $99 \%$ quantile. Sample firms spend an average of 10,235 euro per employee and year on innovation activities.

The questionnaire asks firms whether they allocate the majority of funds for innovation projects at the beginning of a project or in stages. The wording of the question specifically mentions that the staged allocation could be organized along milestones. We conceptualize this information as a dummy variable (Staged) that takes on the value one if firms finance their innovation projects in stages and zero otherwise. Such a staging of innovation projects is reported by $62 \%$ of the firms. Respondents are additionally asked how many steps such a process usually involves. On average this number lies slightly above four. However, due to a particularly low response rate and concerns about measurement error for this specific item, we rely solely on the binary indicator in the subsequent analysis.

To assess the availability of financial resources, we take advantage of a standardized credit rating index (Credit Rating) for German firms that is provided by Creditreform, the largest credit rating agency in Germany (Czarnitzki and Hottenrott, 2011b). Czarnitzki and Hottenrott (2011a) describe the underlying methodology in a detailed way. The index provides data about the creditworthiness of not only large publicly listed companies but also small and medium sized firms that comprise more than $80 \%$ of the observations in our sample. Creditreform ratings are based on a company's general financial situation and past payment history as well as on individual assessment by Creditreform's local staff. This information is provided to banks in order to evaluate credit default risks as well as to other market participants, e.g., suppliers that want to screen their potential partners before engaging in a business relationship. The index ranges from 100 (excellent rating) to 600 (worst rating). A decrease in the integer valued index thus denotes an ameliorated creditworthiness. We drop firms with a rating higher than 500 from the analysis since this case implies severe financial trouble that is equivalent to bankruptcy.

In order to examine the moderating effect of radicalness, we draw on self-reported information about the goals that companies pursue with their innovation activities (see examples by Leiponen and Helfat, 2010; Klingebiel and Rammer, 2014). In the MIP, firms are asked to rate the importance of several innovation objectives on a 4-point Likert scale, where response categories range from not relevant, coded as 0 , to highly relevant, coded as 3. In line with Klingebiel and Rammer (2014), we use firms' ratings of the two objectives to (1) increase the range of products and to (2) enter new markets to construct a binary indicator (Radicalness). In particular, we only regard firms with a compound score of 6 , i.e., firms that attribute a high relevance to both objectives, as envisaging radical innovations. 
The respective question is only included in the 2009 wave of the survey. However, we argue that a firm's focus on incremental versus more radical innovations is stable in the short-run. As explained by Lavie and Rosenkopf (2014), path dependencies reinforce either exploration or exploitation activities. As a result, firms developing incremental innovations are likely to do more incremental innovation in the future; while firms developing more radical innovations are likely to keep up these radical innovation activities. We therefore carry forward the observed Radicalness for firms that appear in both waves. This is the case for about one third of the observations in the 2011 wave, which allows us to extend our sample from the 2009 wave with an additional number of 605 observations, thereby increasing statistical power. In total, $34 \%$ of firms are envisaging more radical innovations.

\subsection{Control variables and timing}

To control for confounding influences, we include other firm level characteristics in our empirical specification. Innovation performance is likely to be influenced by size and experience effects (Veugelers and Cassiman, 1999; Aerts and Schmidt, 2008), measured by the number of employees (Firm Size), as well as the firm's age (Firm Age). The average firm in the sample has 394 employees and is 32 years old. To make project portfolios comparable across firms, we control for the total number of innovation projects (Projects $)^{1}$. Firms in the sample conducted an average number of 15 projects within a period of three years. In addition, the success of innovation activities is contingent on a firm's internal capability to exploit new knowledge and technologies (Cohen and Levinthal, 1990). We account for this by incorporating the firm's share of employees that hold an academic degree (Share of Graduates). At the same time, this measure controls for the quality of labor input. About $26 \%$ of the sample firms' employees hold a university degree. Although our analysis is concerned with new product development, we incorporate a variable representing whether firms introduced a Process Innovation during the prior period (which applies to $61 \%$ of the sample firms) to control for firms' success with this other class of innovation activities. A dummy variable equal to one if a firm is part of an enterprise group (Group), which is the case for $6 \%$ of the firms in the sample, controls for differences in governance structure. Summary statistics for variables in levels are reported in Table 1. Finally we construct a set of 25 industry dummies based on the two-digit NACE (Rev. 2.0) categories and a time dummy, representing the survey waves, to control for time effects (see Table 5 in the Appendix).

Given the skewed distribution of several variables, namely New Product Sales, Innovation Intensity, Firm Size, Firm Age, and Projects, we transformed them logarithmically. Table 6 (Appendix) depicts the correlation structure of the final variables as used in the analysis. Although we have information from two survey waves, we are not able to construct a balanced panel data set of satisfactory size. Thus, we need to rely on pooled cross-section methods (see examples by Laursen and Salter, 2006; Klingebiel and

${ }^{1}$ The Oslo manual makes a distinction between R\&D and innovation activities (OECD, 2005, Section 2.5). Pure R\&D activities are a subset of innovation activities, and the number of Projects hence includes, but is not limited to, pure R\&D projects. 
Rammer, 2014; Cappelli et al., 2014). Fortunately, CIS data has the advantage that many variables cover a period of three years before the survey year $(t$ until $t-2$, with survey year being $t+1)$. New Product Sales, i.e., the dependent variable, is measured at the end of this period (in $t$ ) which therefore reduces simultaneity and allows for a more realistic timing of the underlying relationship. Table 1 shows that this time lag is present for the majority of variables in our dataset.

The continuous variables Innovation Intensity and Firm Size, however, are both measured in $t$ and due to the lack of overlap between waves, we are not able to incorporate lagged values. In this case, one solution would be to rely on data extrapolation. Such an out-of-sample imputation relies on strong assumptions about missing variables that we are uncomfortable with. In consonance with other researchers (Hussinger, 2008; Peters et al., 2013; Cappelli et al., 2014), we rather acknowledge an imperfect timing between innovation expenditures and innovation outcome. To fully analyze the time structure of when effects materialize, one would need to rely on much more detailed longitudinal data than we have at hand ${ }^{2}$. This should be born in mind for the interpretation of our results. Fortunately, for the credit rating index longitudinal data is sufficiently available, which enables us to use a one-year time lag for this variable.

\subsection{Estimation}

We estimate the link between staged project management and innovation performance with a log-log specification, which has the convenient feature that regression coefficients can be interpreted as elasticities. Authors in previous studies (Laursen and Salter, 2006; Leiponen and Helfat, 2010, 2011; Klingebiel and Rammer, 2014) often rely on limited dependent variable models, namely a Tobit type I regression (Tobin, 1958; Amemiya, 1985), because they recognize the non-negativity of sales with new products. In agreement with Angrist and Pischke (2009), we break with this tradition as we do not make sense of a latent variable interpretation with a separate censoring mechanism that forces negative sales to be zero. Rather we think that zeros occur naturally in this setting. Another justification for the Tobit model is sometimes provided by a hurdle model interpretation (Cragg, 1971). Here, the censoring point is thought as a threshold of "participation" which is modeled by a separate probabilistic process. Excess zeros (e.g., relative to the likelihood of a normal distribution) occur because a part of the sample is simply reluctant to engage in any innovation activities. We think that such a two-part approach is not appropriate for our application either as some form of innovation activity is a necessary condition to appear in our sample. In addition, we do not require fitted values to satisfy boundary conditions at the lower ends of the distribution, since we are not interested in effects that appear in certain distributional ranges of the dependent variable. Estimation

\footnotetext{
${ }^{2}$ The longitudinal pattern of all observations in the MIP between 2006 and 2010 is as follows. 25, 382 firms are observed, with a medium number of 3 year observations per firm. $22.6 \%$ of these firms responded in all 5 consecutive years. Other firms show a more unsteady response pattern. The innovation intensity attains a mean value of 0.01 , which approximates the average in our estimation sample. The standard deviation amounts to 0.0221 between firms, and 0.0102 within firms, over time.
} 
by ordinary least squares, in contrast, conveniently allows to incorporate cluster-robust standard errors (clustered at the firm level) which is advisable when analyzing survey data considering that some firms appear in both survey waves.

In our baseline model, we regress New Product Sales on Innovation Intensity interacted with Staged $($ Staged $\times$ Inn. Int.). This has the conceptual advantage that staging innovation projects, as a project management paradigm, can only be complementary to an actual innovation budget. It enhances the efficiency of allocated resources, yet it does not increase innovation outcomes by itself. Interpreting an effect of the Staged dummy alone would fall short of this aspect. In a next step, we augment the full sample estimation with a split sample analysis. To measure the moderating effect of resource availability, we split the sample at a value of the credit rating index being equal to 220, which corresponds to the sample median. It should be mentioned however, that this value indicates still a rather good rating and firms below but close to the threshold cannot be seen as severely financially troubled. A second sample split is done according to the radicalness of the firm's envisaged innovations. In a last step, we interact these two dichotomous variables to generate four mutually exclusive categories (strong credit rating paired with the intent to develop incremental innovations, strong credit rating paired with the intent to develop radical innovations, weak credit rating paired with the intent to develop incremental innovations, and weak credit rating paired with the intent to develop radical innovations).

\section{RESULTS}

Column 1 in Table 2 shows the regression results for the full sample of firms. Innovation Intensity (log), Firm Size (log) and Share of Graduates all have a positive effect on New Product Sales (log). These findings are consistent with recent CIS studies (Klingebiel and Rammer, 2014; Grimpe and Kaiser, 2010; Laursen and Salter, 2006; Leiponen and Helfat, 2010). Firms that belong to a Group and that have more Projects have higher New Product Sales (log). The interaction term of Staged and Innovation Intensity (log) has no significant effect on New Product Sales (log). Hypothesis 1 is hence not confirmed for the full sample. We do however find a positive main effect of Staged on New Product Sales $(\log )$.

The results become more interesting when the sample is split according to Credit Rating and Radicalness. Column 2 in Table 2 contains the regression results for the subsample of firms with a strong Credit Rating (i.e., with a credit rating index below 220). The positive effects of Innovation Intensity (log), Firm Size (log), Share of Graduates, Projects, as well as the positive main effect of Staged remain. In addition, the interaction term of Staged and Innovation Intensity (log) now has a significantly positive effect on New Product Sales (log). These results are strikingly different from those for the subsample of firms with a weak Credit Rating (i.e., with a credit rating index equal to or above 220; see Column 3 in Table 2). For the subsample of resource-constrained firms, we find neither a significant main effect of Staged nor a significant interaction term of Staged and Innovation Intensity (log) on New Product Sales (log). These results 
Table 2: Innovation Performance

\begin{tabular}{lccccc}
\hline \hline & \multicolumn{5}{c}{ New Product Sales $(\log ):$} \\
\cline { 2 - 6 } & Full Sample: & \multicolumn{2}{c}{ Credit Rating: } & \multicolumn{2}{c}{ Radicalness: } \\
& $(1)$ & $(2)$ & $(3)$ & $(4)$ & $(5)$ \\
\hline Staged & $0.856^{* * *}$ & $1.401^{* *}$ & 0.410 & 0.0430 & $1.394^{* * *}$ \\
& $(0.325)$ & $(0.548)$ & $(0.404)$ & $(0.575)$ & $(0.525)$ \\
Innovation Intensity $(\log )$ & $0.156^{* * *}$ & $0.169^{* * *}$ & $0.153^{* * *}$ & $0.192^{* *}$ & $0.176^{* * *}$ \\
& $(0.0369)$ & $(0.0612)$ & $(0.0475)$ & $(0.0830)$ & $(0.0618)$ \\
Staged $\times$ Inn. Int. (log) & 0.0854 & $0.190^{* *}$ & -0.0138 & 0.00126 & $0.177^{* *}$ \\
& $(0.0540)$ & $(0.0905)$ & $(0.0663)$ & $(0.102)$ & $(0.0861)$ \\
Projects (log) & $0.836^{* * *}$ & $0.810^{* * *}$ & $0.752^{* * *}$ & $0.672^{* * *}$ & $0.814^{* * *}$ \\
& $(0.0622)$ & $(0.0850)$ & $(0.0926)$ & $(0.108)$ & $(0.0971)$ \\
Firm Size (log) & $0.659^{* * *}$ & $0.740^{* * *}$ & $0.603^{* * *}$ & $0.886^{* * *}$ & $0.595^{* * *}$ \\
Firm Age (log) & $(0.0474)$ & $(0.0710)$ & $(0.0682)$ & $(0.0858)$ & $(0.0713)$ \\
Share of Graduates & -0.0574 & 0.0923 & $-0.195^{* *}$ & $-0.198^{*}$ & 0.0191 \\
& $(0.0648)$ & $(0.110)$ & $(0.0984)$ & $(0.118)$ & $(0.0983)$ \\
Process Innovation & $1.400^{* * *}$ & $1.475^{* * *}$ & $1.486^{* * *}$ & $1.031^{* *}$ & $1.115^{* *}$ \\
Group & $(0.270)$ & $(0.566)$ & $(0.314)$ & $(0.434)$ & $(0.441)$ \\
Constant & -0.0216 & -0.102 & 0.0420 & -0.0704 & -0.0101 \\
& $(0.117)$ & $(0.192)$ & $(0.153)$ & $(0.222)$ & $(0.179)$ \\
& $0.578^{* *}$ & 0.384 & 0.564 & 0.340 & $0.831^{*}$ \\
Observations & $(0.262)$ & $(0.360)$ & $(0.406)$ & $(0.394)$ & $(0.431)$ \\
Adjusted R ${ }^{2}$ & $-5.314^{* * *}$ & $-6.488^{* * *}$ & $-4.275^{* * *}$ & $-5.585^{* * *}$ & $-5.118^{* * *}$ \\
\hline & $(0.810)$ & $(1.187)$ & $(1.316)$ & $(1.280)$ & $(1.584)$ \\
\hline
\end{tabular}

Cluster-robust standard errors in parentheses: ${ }^{*} p<0.10,{ }^{* *} p<0.05,{ }^{* * *} p<0.01$

Industry and time dummies included. Sample split: (2) strong credit rating, (3) weak credit rating, (4) envisaging radical innovations, (5) envisaging incremental innovations 
confirm Hypothesis 2 that the moderating effect of staging innovation projects is lower for resource-constrained firms than for resource-abundant firms.

To assess the validity of Hypothesis 3, we use the binary variable Radicalness to split the sample into a subsample of firms that envisage more radical innovations (Column 4 in Table 2) and a subsample of firms that have continuous or incremental innovation aspirations (Column 5 in Table 2). We again find that Innovation Intensity (log), Firm Size (log), Share of Graduates, and Projects have a significant positive effect on New Product Sales (log) for both subsamples. However, while Staged has a positive main effect and a positive interaction effect for the subsample of firms with incremental innovation aspirations, these effects are absent for the subset of firms envisaging more radical innovations. These results confirm Hypothesis 3 that the moderating effect of staging innovation projects is lower for firms envisaging more radical innovations.

Table 3 interacts the sample splits according to Credit Rating and to Radicalness with each other. The results show that the positive main effect and the positive moderating effect of Staged only hold for the subset of firms having better credit ratings than the median firm and that aspire continuous or incremental innovations (Column 3 in Table 3). For all other subsamples, no significant effect of Staged, neither direct nor moderating, on New Product Sales (log) is found.

\subsection{Robustness checks}

We conduct several robustness checks for our results. For the sake of brevity they are not reported but available upon request to the authors. To arrive at the Radicalness indicator, we impute values for the 2011 wave when firms are observed in both waves. This approach allows us to expand our sample and gain statistical power. To check the sensitivity of our results to this procedure, we estimate the same specification as presented in Table 2 with the 2009 wave only. Despite the reduced sample size, our results remain robust.

A sample split at the median of Credit Rating is an arbitrary choice. The distribution of the index has a lot of mass at intermediate values of the support, which results in a threshold that still corresponds to a comparatively good rating. As a robustness check, and to further differentiate resource-constrained from resource-abundant firms, we refine the division in subsamples according to the $33 \%$ and $66 \%$ quantile of Credit Rating. The estimated interaction terms (Staged, Staged $\times$ Inn. Int.) are jointly significant in the samples of firms with good (minimum until 33\% quantile) and intermediate (33\% until $66 \%$ quantile) rankings. Point estimates increase over the three subsamples, which suggests a monotone relationship between resource availability and the success of staging innovation projects.

Due to a high correlation between Firm Size and Projects (0.47 in logarithms), one might be concerned about collinearity. If the number of innovation projects is scaled by firm sales, to arrive at a measure that is orthogonal to firm size, results remain virtually identical. We thus stick to the previous specification as it offers a more natural interpretation. 
Table 3: Interacted Categories

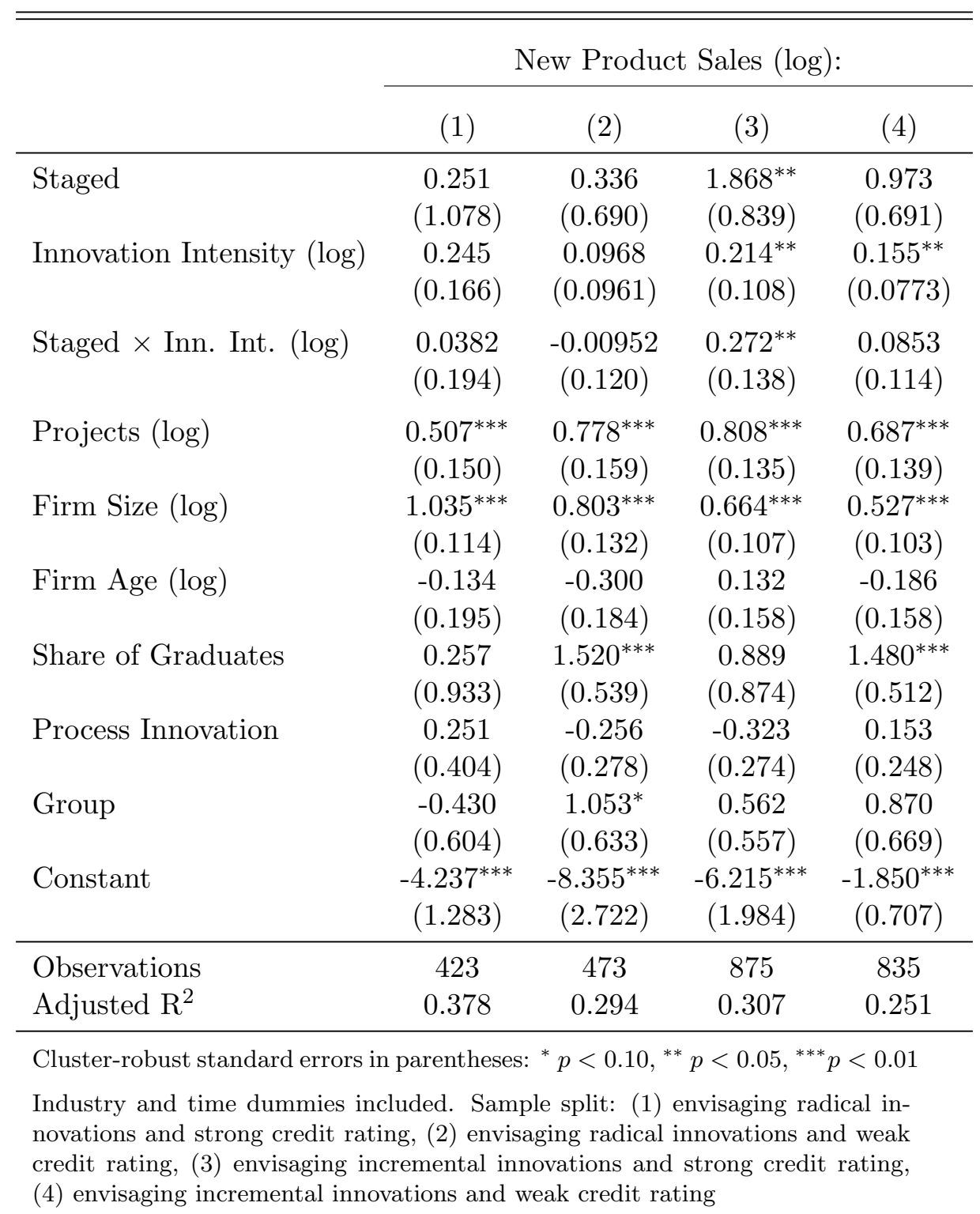


Eventually, we address two aspects in which we depart from the empirical strategy in previous related studies. Klingebiel and Rammer (2014) construct a variable measuring the radicalness of a firms' envisaged innovations with the same data on innovation objectives as we do. They also rely on the compound score of the two objectives to enter new markets and to expand into new product categories. However, they omit firms from the analysis if scores of the individual items (0 to 3) sum up to 5. In agreement with the robustness checks for their results, we find no sensitivity to this alternative conceptualization. Furthermore, we refer to the previous discussion of limited dependent variable models by reestimating our specification with a Tobit type I model. As point estimates remain close to our original results, we are confident about the robustness of our analysis.

\subsection{Additional insights into resource-abundant and resource-constrained firms}

In the literature background section, we hypothesized that companies with less financial resources generally benefit less from staging their innovation projects. While the results presented above confirm our hypothesis, the MIP also offers some possibilities to look deeper into the mechanisms behind this relationship. In line with the literature, we argue that staged project management has an effect on the project portfolio of a firm. In particular, staged project management potentially allows firms to reap the option values of postponing and abandoning projects. By investigating whether firms that successfully apply the staging of innovation projects differ from their unsuccessful counterparts with respect to postponing and abandoning projects, we can further shed light on the influence of innovation project management on innovation output. We conduct this analysis for the sample split according to firms' credit rating because resource-constrained firms might be particularly prone to non-optimal decisions of project abandonment as discussed in the literature background section above.

We make use of additional questions in the two waves of the MIP. In particular, the survey asks respondents to provide more detailed information about the total number of innovation projects in the last three years and to differentiate between successful projects (Successfully Completed Projects), projects that have been discontinued before completion (Abandoned Projects), and projects that are still ongoing (Ongoing Projects). Category averages, relative to a firm's total number of innovation projects, are $50 \%$ successfully completed, $8 \%$ abandoned, and $40 \%$ ongoing projects. Note that these numbers do not necessarily need to add up to one because of missing values in some response categories. By looking at whether staged project management has a different effect on the relative shares of successfully completed, abandoned, and ongoing projects in the portfolio of resource-abundant versus resource-constrained firms, we can gain a better understanding of why these two types of firms do not benefit equally from staging innovation projects.

For this purpose, we estimate a fractional response model (Papke and Wooldridge, 1996), again applying a sample split at the median of Credit Rating. This model assumes a set of linear predictors (explanatory variables) to be related to the conditional mean 


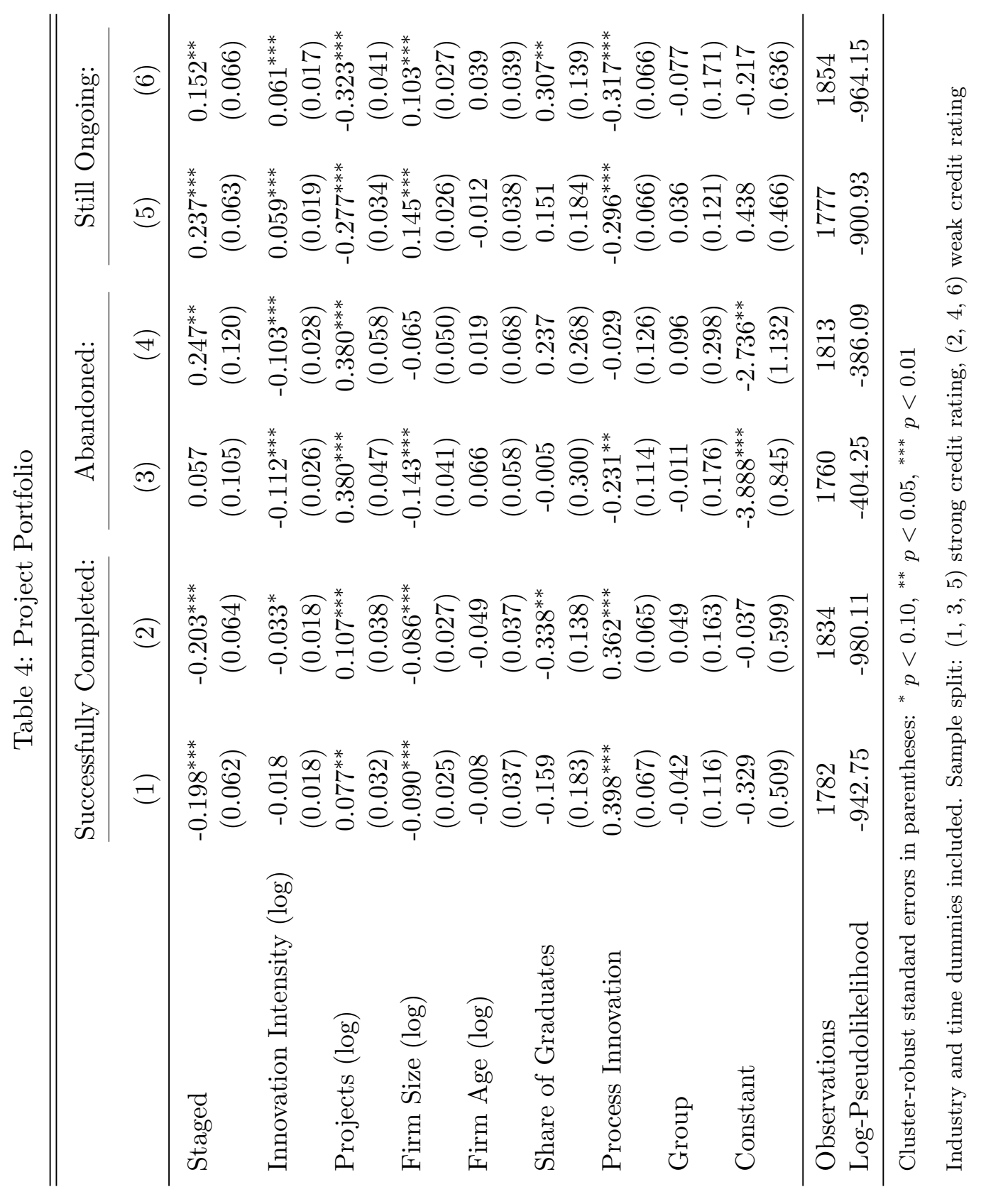


of the data through a logistic link function. It is therefore consistent with dependent variables that solely take on values between zero and one. Furthermore, as the loglikelihood for the fractional response model is part of the linear exponential family, the approach is robust to distributional misspecification as long as the conditional mean is correctly specified (Gourieroux et al., 1984). We estimate the model by GLM (Nelder and Wedderburn, 1972) but rely again on cluster-robust inference since GLM standard errors will be inconsistent due to repeated observations of the same firm in the sample (Hardin and Hilbe, 2012). As the response rate for these respective items is significantly lower than for the variables used in our main specification, the estimation sample is reduced by more than $50 \%$.

Columns 1 and 2 in Table 4 show that the use of a staged project management approach is associated with a significantly lower share of successfully completed projects, for both firms with strong and for firms with weak credit ratings. At the same time, one can observe an increased share of abandoned projects for firms with weak credit ratings (Column 4 in Table 4). Firms with strong credit ratings do not abandon a higher share of projects when using staged project management. Instead, they show a high share of projects that are still ongoing.

\section{DISCUSSION}

The commercialization of new products and services is an essential determinant of longrun survival in a dynamic economic environment. However, due to technological and market uncertainties, only a fraction of a firm's innovation projects turns into a true commercial success. In times of budgetary restrictions, expenditures on innovation are under pressure and firms have to think carefully about how to manage their innovation projects in order to maximize the return on investment. By empirically demonstrating the effect of staged project management on sales from new products, this article advances our understanding of the determinants of firms' innovation performance. The results show that this effect depends heavily on firms' characteristics and ambitions, in particular on the resources the firm has at its disposal, and on whether it aspires incremental or more radical innovations. As discussed below, these findings have implications for real options reasoning and innovation project management.

We hypothesized a moderating effect of staged project management, in the sense that the management of innovation projects in stages increases the effect of innovation inputs (i.e., innovation expenditures) on innovation outputs (i.e., sales from new products). Our empirical results show this moderating effect to be highly dependent on whether or not a firm envisages radical innovations that increase the firm's product range and allow it to enter new markets. Staging innovation projects requires the upfront identification of milestones and criteria for continuation or abandonment. When firms envisage incremental or continuous innovations, projects have a fixed technical agenda and fixed target market (Adner and Levinthal, 2004). Questions of commercialization and the development of institutional structures can be considered sequential to technological issues (Garud et al., 1998). For this type of incremental innovation projects, it is possible to identify appropriate milestones and exit criteria upfront. By using these milestones and 
criteria, firms become more successful at developing incremental innovations. Staged project management thus enhances the effectiveness of innovation investments to generate sales from incremental or continuous innovations.

However, when more radical product innovations are envisaged, our results show no effect of staged project management on innovation performance. Staged innovation projects, with predetermined milestones and criteria, are not beneficial for the development of this type of radical innovations, where goals are often unclear. A project may not meet its initial expectations, but it can nevertheless lead to the discovery of unanticipated possibilities and thereby enable the development of radical innovations in subsequent projects (Phillips et al., 2006). Although our research set-up does not allow for an explicit test, these results suggest that for radical innovation projects a more experimental approach with flexible deliverables and possible detours is preferable (Eisendardt and Tabrizi, 1995). This implies that firms should adapt their project management approach depending on the radical or incremental character of their envisaged innovations.

Furthermore, our study highlights the important role of resource-availability for the effective implementation of a staged project management approach. While the approach allows resource-abundant firms to generate higher sales from investments in innovation, this effect does not occur for firms that have fewer resources at their disposal. These results provide initial support for the argumentation that, because they are more likely to exit potentially promising projects, and because they are less equipped to deal with the greater complexity inherent to staging innovation projects, companies with less financial resources generally benefit less from staging their innovation projects.

Our data also allow us to investigate the role of innovation project management in more detail. By looking at whether staged project management is associated with different portfolio shares of successfully completed, abandoned, and ongoing projects in resourceabundant versus resource constrained firms, we gain a better understanding of why these two types of firms do not benefit equally from staged project management. Within the covered period, the share of successfully completed projects of resource-abundant firms is reduced to the advantage of ongoing projects, while the proportion of abandoned projects remains unaltered. This result suggests that resource-abundant firms benefit from staged project management not because it helps them to abandon unpromising projects, but because it allows them to delay project decisions until additional information necessary for informed decision making becomes available. Hence, they exercise the option value of waiting and benefit from the flexibility to adjust their innovation strategy to changing economic conditions. As for resource-constrained firms, our results demonstrate that they are inclined to cut away more projects when using staged project management. We again find a decreased share of successfully completed projects, which are now, however, accompanied by an increased proportion of abandoned projects. This result implies that resource-constrained firms shift resources and focus on fewer projects when applying a staged approach. Yet, it is surprising that their sales figures stemming from innovative products do not benefit from this reallocation of resources.

Our findings on project continuation and abandonment rates contribute to the literature on real options reasoning. Several authors have argued that to truly understand 
the value of real options reasoning, more insight into the mechanisms underlying the approach is needed. Driouchi and Bennett (2012), for example, point out that because of the reluctance of firms to disclose their real options activities, there is no particular study which explicitly inspects the effect of real options decision-making on performance. There is some evidence of the positive impact of staged project management on outcomes of superior new products (Davis, 2002; Soh et al., 2004), but very little is done to open this "black box" and to shape our understanding of the mechanisms at play (Ettlie and Elsenbach, 2007). Adner and Levinthal (2004) argue that, in order to truly understand the impact of real options reasoning, one should move beyond studying whether projects are on average more profitable in firms using real options, and "examine the way in which the portfolio is adjusted over time and, in particular, firms' approaches to abandonment" (Adner and Levinthal, 2004, pp. 83).

It is generally believed that the value of applying real options reasoning results from two distinct mechanisms: (1) the possibility to delay project decisions until uncertainty is reduced, and (2) the possibility to abandon unsuccessful projects and reinvest the budget into other more promising projects. We observe that the use of a staged project management approach in resource-abundant firms is associated with a decreased share of successfully completed projects to the advantage of ongoing projects, while keeping the proportion of abandoned projects stable. Resource-abundant firms hence use the staged approach mainly to capture the value inherent in waiting. They are able to use this additional flexibility to their advantage in dealing with the large uncertainties related to innovation projects, that only slowly resolve over time. The performance premium of innovation expenditures in generating sales from new products for this group underpins this interpretation. By contrast, resource-constrained firms are inclined to cut away more projects when using staged project management. They use the approach mainly to capture the value in abandoning. Compared to their counterparts with more resource slack, they spend their, usually, smaller innovation budget on fewer projects. This means that they concentrate their resources on seemingly more promising ventures when applying staged project management. Looking at innovation performance, however, we do not see that this additional focus is profitable. We infer from this finding that the positive selection effect is outweighed by go-or-kill decisions that are made too early, at stages where uncertainty is still high and informed decisions about the prospects in terms of commercial success are still infeasible. The tight budgets that managers face lead them to veer off course too soon rather than sitting out the gales associated with their endeavor.

Overall, we find convincing evidence that staged project management has the potential to unleash the value in delaying project decisions until more information becomes available. We also demonstrate that a staged project management approach allows certain firms to abandon projects more easily, thereby concentrating the allocated funds, but not necessarily improving innovation performance. Successfully exploiting the potential of staging innovation projects in fostering innovation output thus requires perseverance. Resource-constrained firms hoping to use a staged approach as a leverage for dynamism and renewal may end up disappointed if they are unable to mobilize the necessary resources to stay in the game until chances and risks become assessable. 
While the literature on real options reasoning is characterized by substantial debates between "believers" and "non-believers" of real options reasoning and staged project management, this article is one of the first to delineate under which conditions staged project management is beneficial and under which conditions it is not. It thereby accommodates a strong plea in the literature for a more contingent view on real options reasoning (Driouchi and Bennett, 2012) and on project management (Loch, 2000; Phillips et al., 2006; Biazzo, 2009). It empirically shows the value of staged project management for resource-abundant firms envisaging incremental innovations. At the same time, it demonstrates that the approach does not improve innovation performance if resources are scarce or radical innovations are envisaged. By explicating these conditions empirically, this article highlights the risk of a one-size-fits-all approach to innovation project management. It also allows the literature to advance beyond the mere discussion on whether or not real options reasoning and staged project management make sense. In particular, it shifts the focus for further research and theoretical development to (1) studying the phenomenon in the contexts in which it is proven relevant, i.e., in resourceabundant firms with modest innovation ambitions, and (2) investigating more in-depth why real options reasoning - and staged project management in particular - does not work when resources are scarce or innovation ambitions are high.

\section{LIMITATIONS AND FURTHER RESEARCH}

The present study leaves room for improvement and further research. As noted above, although the data were collected in two consecutive waves of the German CIS, the limited overlap between the two waves does not allow to exploit the panel structure of the survey. Instead, cross-sectional analyses were performed. Even though the CIS has the advantage that many variables cover a period of three years preceding the measurement of our dependent variable, sales from new products, panel studies on this topic would allow to control for time-invariant unobserved heterogeneity. A caveat is, however, that such a study would rely on variation over time to identify the parameters of interest. In our data, the between-variation of staged project management is larger than within firms. Therefore, the use of a staged approach could also be seen as part of the unobserved heterogeneity in productivity that the introduction of fixed effects would pick up. Nonetheless, a longitudinal study allows for encompassing timing issues. The present approach measures short-term performance only, but radical innovations may take more time to materialize into sales. Research with a longer-term perspective could hence measure the performance effect of staged project management more precisely, especially when more radical innovations are envisaged.

We investigate the relationship between staged project management and innovation output. We show that the effect is moderated by whether firms envisage incremental or radical innovations and by the availability of financial resources. In a subsequent investigation, we narrow down our analysis to the mechanisms through which a staged approach can take a positive effect on performance within a firm. We compare resource-abundant and resource-constrained firms because the literature suggests that there are potential downsides of staged project management, which are likely to depend on firm character- 
istics such as resource availability. We find that the group that benefits from staging innovation projects, i.e., resource-abundant firms, takes advantage of the waiting value of real options to increase strategic flexibility. In the group in which staged project management remains ineffective, i.e., resource-constrained firms, resources are reallocated to fewer projects, but there is no performance premium related to this additional focus. Unfortunately, we do not have detailed data about the conducted projects and can only rely on their number and status of completion within a firm. This is why we are unable to investigate the direct link between a firm's project portfolio and its innovation performance. Our analysis provides indication that staging innovation projects develops its potential through an increased strategic flexibility in a firm's project management, resulting in longer project execution times, although this interpretation mainly remains theory-based. We cannot exclude the possibility that there are other mechanisms that create the effect or add to it. We thus would like to see future studies exploring the interplay of real options reasoning, project execution and innovation performance in a more detailed way. This research could study the decision to abandon projects, and could examine whether and how some firms are able to capture both the value of waiting and the value of abandoning at the same time, thereby illuminating the black box even further.

The firm level perspective that this article takes is also restrictive in another sense. While we capture the innovation ambition at the level of the organization as a whole, individual firm projects will of course differ with respect to their innovative ambition, i.e., whether they envisage developing incremental or more radical innovations. Projects may also differ with respect to the quality of the ideas that are fed into them. Therefore, future research might try to study the performance effect of staged project management on a project level. This could provide insight into the different project management approaches needed for incremental versus more radical innovations. In addition, qualitative research at the level of the firm could explore how companies can organize for a combination of both types of innovation projects, and whether experimental approaches with flexible deliverables and possible detours are indeed more valuable when radical innovations are of concern.

\section{CONCLUSION}

If firms want to survive in the long run, the development and commercialization of new products and services are essential. However, innovation processes are costly and outcomes are often uncertain. This article investigates whether a staged approach to innovation projects allows firms to reap more benefits from its expenditures for innovation. We theorize that a staged approach affects the relationship between innovation inputs and innovation output differently depending on project and firm characteristics.

In particular, we demonstrate that the moderating effect of a staged approach is absent for firms with more radical innovation aspirations, for which the predetermined milestones and criteria inherent to staged innovation projects are inappropriate. In addition, we show that a staged approach has no effect when firms are resource-constrained. We explain this finding further and demonstrate that resource-constrained firms are in- 
clined to cut away more projects when using staged project management. They use the approach mainly to shift resources to fewer projects and to capture the value in abandoning. Our findings suggest that this selection of projects is ineffective in stimulating innovation output. We conclude that, because of budgetary pressure, resourceconstrained firms need to decide on abandonment at points of time when uncertainty is insufficiently resolved. Resource-abundant firms, by contrast, are shown to delay more projects when using a staged approach, thereby capturing the value inherent in waiting.

This paper accommodates a longstanding plea for a contingency approach in real options reasoning and project management literature, by delineating the circumstances under which the use of a staged project management approach can increase the benefits from investments in innovation. Moreover, by looking into the actual project completion, termination, and continuation rates, we contribute to theory on real options reasoning in general, and in particular to insights regarding the value inherent in abandoning and waiting.

\section{REFERENCES}

Abernathy, W. J. and Utterback, J. M. (1987). Patterns of industrial innovation. Technology Review, pages 40-47.

Adner, R. (2007). Real options and resource reallocation processes. Advances in Strategic Management, 24:363-372.

Adner, R. and Levinthal, D. A. (2004). What Is Not a Real Option: Considering Boundaries for the Application of Real Options to Business Strategy. Academy of Management Review, 29(1):74-85.

Aerts, K. and Schmidt, T. (2008). Two for the price of one? Additionality effects of R\&D subsidies: A comparison between Flanders and Germany. Research Policy, $37: 806-822$.

Amemiya, T. (1985). Advanced Econometrics. Harvard University Press, Cambridge, MA.

Angrist, J. D. and Pischke, J.-S. (2009). Mostly Harmless Econometrics: An Empiricist's Companion. Princeton University Press.

Barczak, G., Griffin, A., and Kahn, K. B. (2009). Perspectives: Trends and drivers of success in NPD practices: results of the 2003 PDMA best practices study. Journal of Product Innovation Management, 26:3-23.

Barnett, M. L. (2008). An attention-based view of real options reasoning. Academy of Management Review, 33:606-628.

Belderbos, R., Caree, M., Diederen, B., Lokshin, B., and Veugelers, R. (2004). Heterogeneity in R\&D cooperation strategies. International Journal of Industrial Organization, 22:1237-1263. 
Benner, M. and Tushman, M. (2003). Exploitation, exploration, and process management: the productivity dilemma revisited. Academy of Management Review, 28:238256.

Biazzo, S. (2009). Flexibility, structuration and simultaneity in new product development. Journal of Product Innovation Management, 26:336-353.

Bowman, E. H. and Hurry, D. (1993). Strategy through the options lens: an integrated view of resource investments and the incremental-choice process. Academy of Management Review, 18:760-782.

Brown, S. L. and Eisenhardt, K. M. (1997). The art of continuous change: linking complexity theory and time-paced evolution in relentlessly shifting organizations. Administrative Science Quarterly, 42:1-34.

Cappelli, R., Czarnitzki, D., and Kraft, K. (2014). Sources of spillovers for imitation and innovation. Research Policy, 43:115-120.

Carr, N. (2002). Unreal options. Harvard Business Review, 80(22).

Cassiman, B. and Veugelers, R. (2002). R\&D Cooperation and Spillovers: Some Empirical Evidence from Belgium. The American Economic Review, 92(4):1169-1184.

Coff, R. W. and Laverty, K. . J. (2001). Real options of knowledge assets: Panacea or Pandora's box? Business Horizons, 44(6):73-79.

Cohen, W. M. and Levinthal, D. A. (1990). Absorptive Capacity: A New Perspective on Learning and Innovation. Administrative Science Quarterly, 35(1):128-152.

Cooper, R. G. (2008). Perspective: The Stage-Gate Idea-to-Launch Process - Update, What's New, and NexGen Systems. The Journal of Product Innovation Management, 25:213-232.

Cragg, J. G. (1971). Some Statistical Models for Limited Dependent Variables with Application to the Demand for Durable Goods. Econometrica, 39:829-844.

Crawford, C. M. and Di Benedetto, C. A. (2008). New products management. Mc-GrawHill, Irwin, Burr Ridge, IL.

Crépon, B., Duguet, E., and Mairesse, J. (1998). Research, innovation and productivity: an econometric analysis at the firm level. Economics of Innovation and New Technology, 7:115-158.

Czarnitzki, D. and Hottenrott, H. (2011a). Financial constraints: routine versus cutting edge R\&D investment. Journal of Economics \&3 Management Strategy, 20(1):121-157.

Czarnitzki, D. and Hottenrott, H. (2011b). R\&D investment and financing constraints of small and medium-sized firms. Small Business Economics, 36:65-83. 
Czarnitzki, D. and Toole, A. (2011). Patent protection, market uncertainty, and R\&D investment. The Review of Economics and Statistics, 93(1):147-159.

Davis, C. R. (2002). Calculated risk: a framework for evaluating product development. MIT Sloan Management Review, pages 71-77.

Dewar, R. D. and Dutton, J. E. (1986). The adoption of radical and incremental innovations: an empirical analysis. Management Science, 32:1422-1433.

Dixit, A. K. and Pindyck, R. S. (1994). Investment under Uncertainty. Princeton University Press, Princeton, NJ.

Driouchi, T. and Bennett, D. J. (2012). Real Options in Management and Organizational Strategy: A Review of Decision-making and Performance Implications. International Journal of Management Reviews, 14:39-62.

Eisendardt, K. M. and Tabrizi, B. N. (1995). Accelerating adaptive processes: product innovation in the global computer industry. Administrative Science Quarterly, 40:84110 .

Ettlie, J. E. and Elsenbach, J. M. (2007). Modified stage-gate regimes in new product development. Journal of Product Innovation Management, 24:20-33.

Garud, R., Kumaraswamy, A., and Nayyar, P. (1998). Real options or fool's gold? Perspective makes the difference. Academy of Management Review, 23(2):212-214.

Gourieroux, C., Monfort, A., and Trognon, A. (1984). Pseudo Maximum Likelihood Methods: Theory. Econometrica, 52(3):681-700.

Griffin, A. (1997). PDMA research on new product development practices: updating trends and benchmarking best practices. Journal of Product Innovation Management, 14(6):429-458.

Grimpe, C. and Kaiser, U. (2010). Balancing Internal and External Knowledge Acquisition: The Gains and Pains of R\&D Outsourcing. Journal of Management Studies, 47(8):1483-1509.

Hardin, J. W. and Hilbe, J. M. (2012). Generalized Linear Models and Extensions. Stata Press, College Station, Texas, 3rd edition.

Hart, S., Hultink, E. J., Tzokas, N., and Commandeur, H. R. (2003). Industrial companies' evaluation criteria in new product development gates. Journal of Product Innovation Management, 20:22-36.

Hauser, J., Tellis, G. J., and Griffin, A. (2006). Research on innovation: A review and agenda for marketing science. Marketing Science, 25:687-717.

Huber, G. P. (1991). Organizational learning: The contribution processes and the literatures. Organization Science, 2:88-115. 
Hussinger, K. (2008). R\&D and subsidies at the firm level: an application of parametric and semiparametric two-step selection models. Journal of Applied Econometrics, 23:729-747.

Klingebiel, R. and Rammer, C. (2014). Resource Allocation Strategy for Innovation Portfolio Management. Strategic Management Journal, 35:246-268.

Kogut, B. (1989). A note on global strategies. Strategic Management Journal, 10(4):383389.

Kogut, B. and Kulatilaka, N. (1994). Options thinking and platform investments: investing in opportunity. California Management Review, 36:52-71.

Laursen, K. and Salter, A. (2006). Open for innovation: the role of openness in explaining innovation performance among UK manufacturing firms. Strategic Management Journal, 27(2):131-150.

Lavie, D. and Rosenkopf, L. (2014). Do ties really bind? The effect of knowledge and commercialization networks on opposition to standards. Academy of Management Journal, 57(2):515-540.

Leiponen, A. and Helfat, C. E. (2010). Innovation Objectives, Knowledge Sources, and the Benefit of Breadth. Strategic Management Journal, 31:224-236.

Leiponen, A. and Helfat, C. E. (2011). Location, Decentralization, and Knowledge Sources for Innovation. Organization Science, 22(3):641-658.

Loch, C. (2000). Tailoring Product Development to Strategy: Case of a European Technology Manufacturer. European Management Journal, 18(6):246-258.

McDonald, R. and Siegel, D. (1986). The value of waiting to invest. Quarterly Journal of Economics, 101(4):707-727.

McGrath, R. G. (1999). Falling forward: real options reasoning and entrepreneurial failure. Academy of Management Review, 24(1):13-30.

Miller, K. D. (2002). Knowledge inventories and managerial myopia. Strategic Management Journal, 23:689-706.

Miller, K. D. and Arikan, A. (2004). Technology search investments: evolutionary, option reasoning, and option pricing approaches. Strategic Management Journal, 25:473-485.

Nelder, J. A. and Wedderburn, R. W. M. (1972). Generalized Linear Models. Journal of the Royal Statistical Society. Series A (General), 135(3):370-384.

OECD (2005). Oslo Manual: Guidelines for Collecting and Interpreting Innovation Data. OECD, Paris, 3rd edition. 
Oorschot, K. V., Sengupta, K., Akkermans, H., and van Wassenhove, L. (2010). Get Fat Fast: Surviving Stage-Gate in NPD. The Journal of Product Innovation Management, $27: 828-839$.

Papke, L. E. and Wooldridge, J. M. (1996). Econometric Methods for Fractional Response Variables with an Application to 401 (K) Plan Participation Rates. Journal of Applied Econometrics, 11:619-632.

Peters, B., Roberts, M. J., Vuong, V. A., and Fryges, H. (2013). Estimating Dynamic R\&D Demand: An Analysis of Costs and Long-Run Benefits. NBER Working Paper No. 19374 .

Phillips, W., Noke, H., Bessant, J., and Lamming, R. (2006). Beyond the steady state: managing discontinuous product and process innovation. International Journal of Innovation Management, 10(2):175-196.

Rangan, S. (1998). Do multinationals operate flexibly. Journal of International Business Studies, 29(2):217-237.

Shane, S. and Ulrich, K. (2004). Technological innovation, product development, and entrepreneurship in management science. Management Science, 50:133-144.

Shenhar, A. J. and Dvir, D. (1996). Toward a typological theory of project management. Research Policy, 25:607-632.

Soh, P., Mahmood, I. P., and Mitchell, W. (2004). Dynamic Inducements in R\&D Investment: Market Signals and Network Locations. The Academy of Management Journal, 47(6):907-917.

Song, M., Di Benedetto, C. A., and Nason, R. W. (2007). Capabilities and financial performance: The moderating effect of strategic type. Journal of the Academy of Marketing Science, 35:18-34.

Summers, G. J. and Scherpereel, C. M. (2008). Decision making in product development: are you outside-in or inside-out? Management Decision, 46(9):1299-1312.

Tobin, J. (1958). Estimation of Relationships for Limited Dependent Variables. Econometrica, 26:24-36.

Tong, T. W. and Reuer, J. J. (2006). Firm and industry influences on the value of growth options. Strategic Organization, 4(1):71-95.

Tong, T. W. and Reuer, J. J. (2007). Real options in multinational corporations: organizational challenges and risk implications. Journal of International Business Studies, $38(2): 215-230$.

Veugelers, R. and Cassiman, B. (1999). Make and buy in innovation strategies: evidence from Belgian manufacturing firms. Research Policy, 28:63-80. 
Zaltman, G., Duncan, R. L., and Holbek, J. (1973). Innovations and Organizations. Wiley, New York. 


\section{APPENDIX}

Table 5: Industry and Time Dummies

\begin{tabular}{llrr}
\hline \hline Industries & NACE (Rev. 2.0) & Observations & Proportion \\
\hline Food/Beverages/Tobacco & $10,11,12$ & 134 & $3.48 \%$ \\
Textiles/Clothing & $13,14,15$ & 115 & $2.98 \%$ \\
Wood/Paper & 16,17 & 97 & $2.52 \%$ \\
Chemicals/Pharmaceuticals & 20,21 & 199 & $5.16 \%$ \\
Rubber/Plastics & 22 & 118 & $3.06 \%$ \\
Glass/Ceramics/Concrete & 23 & 98 & $2.54 \%$ \\
Metals & 24,25 & 289 & $7.50 \%$ \\
Electronics/Electrical & 26,27 & 467 & $12.12 \%$ \\
Machinery/Equipment & 28,33 & 421 & $10.93 \%$ \\
Vehicles & 29,30 & 128 & $3.32 \%$ \\
Furniture/Other Manufacturing & 31,32 & 133 & $3.45 \%$ \\
Energy/Mining/Oil & $5,6,7,8,9,19,35$ & 79 & $2.05 \%$ \\
Water Supply/Waste/Recycling & $36,37,38,39$ & 135 & $3.50 \%$ \\
Wholesale Trade & 46 & 79 & $2.05 \%$ \\
Transportation/Postal Services & $49,50,51,52,53,79$ & 148 & $3.84 \%$ \\
Printing/Publishing/Media & $18,58,59,60$ & 170 & $4.41 \%$ \\
IT-Services/Telecommunications & $61,62,63$ & 271 & $7.03 \%$ \\
Financial Intermediation & $64,65,66$ & 111 & $2.88 \%$ \\
Consulting/Advertising & $69,70,73$ & 152 & $3.94 \%$ \\
Technical Engineering/R\&D & 71,72 & 332 & $8.62 \%$ \\
Other Producer Services & $74,78,80,81,82$ & 121 & $3.14 \%$ \\
Construction & $40,41,42,43$ & 14 & $0.36 \%$ \\
Retail Trade/Motor Vehicle Repair & 45,47 & 12 & $0.31 \%$ \\
Real Estate/Rental Services & 68,77 & 15 & $0.39 \%$ \\
Others & $1,56,85,86,90$ & 15 & $0.39 \%$ \\
\hline Time (survey year): 2009 & & 2122 & $55.07 \%$ \\
& & 1731 & $44.93 \%$ \\
\hline
\end{tabular}




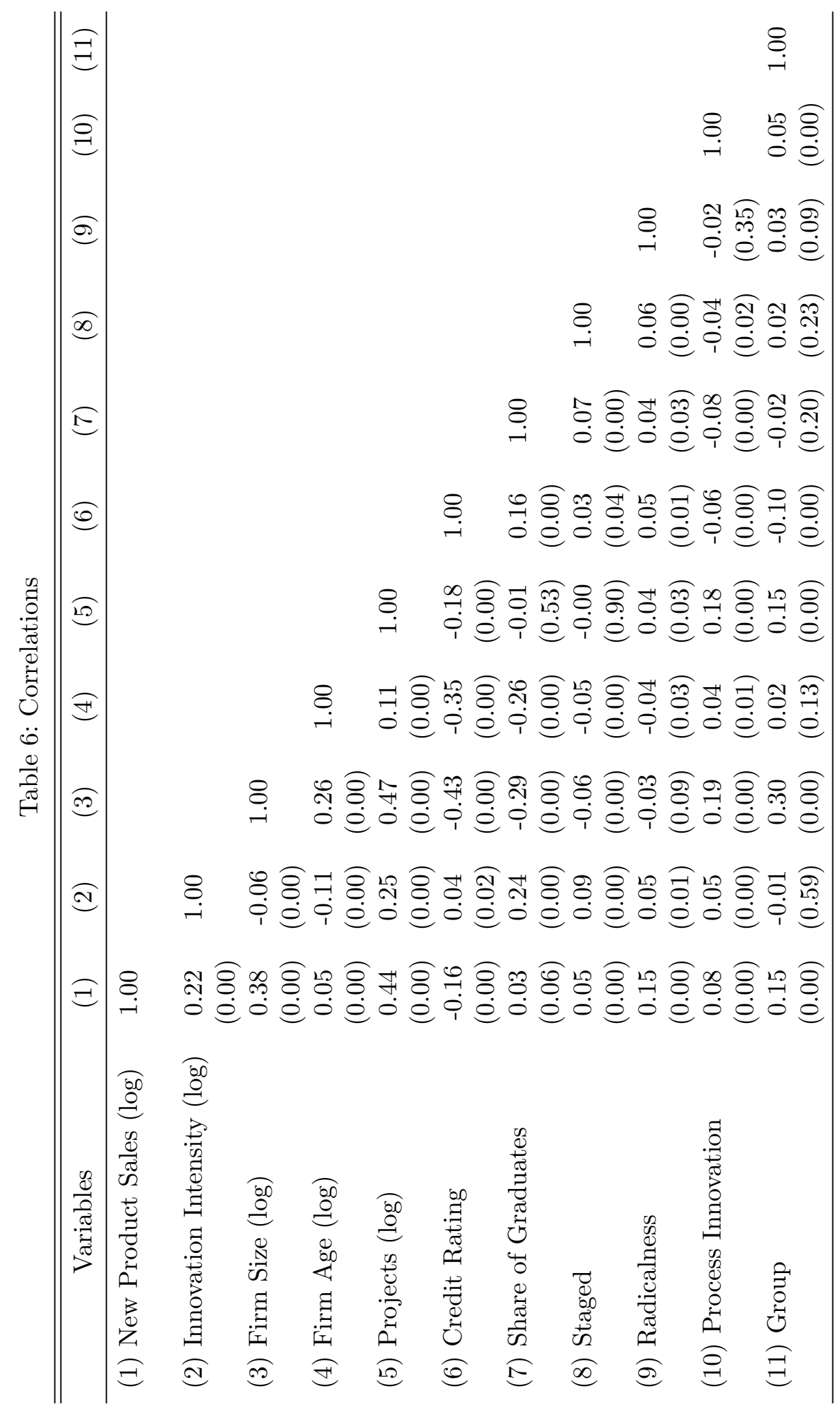

